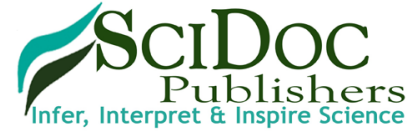

International Journal of Forensic Science \& Pathology (IJFP) ISSN 2332-287X

\title{
Correlation of Troponin T Levels in the Cardiac Sudden Death Cases at Hospital Kuala Lumpur
}

\author{
Case Report
}

Lai $\mathrm{PS}^{1 *}$, Nur Shafina $\mathrm{M}^{2}$, Mohd Hilmi $\mathrm{S}^{1}$, Nur Shazuwani $\mathrm{R}^{1}$, Normaizuwana $\mathrm{MM}^{3}$, Kunasilan $\mathrm{S}^{4}$

${ }^{1}$ Forensic Scientific Officer, National Institute Of Forensic Medicine, Hospital Kuala Lumpur, Ministry Of Health, Malaysia.

${ }^{2}$ Biochemcial Science Officer, Pathology Department, Hospital Kuala Lumpur, Ministry Of Health, Malaysia.

${ }^{3}$ Chemical Pathologist, Pathology Department, Hospital Kuala Lumpur, Ministry Of Health, Malaysia.

${ }^{4}$ Forensic Clinical Specialist, National Institute Of Forensic Medicine, Hospital Kuala Lumpur, Ministry Of Health, Malaysia.

\section{Abstract}

Cardiac deaths accounted for $50 \%$ of all deaths in the developed and one fourth in the developing world. Sudden cardiac death due to an acute myocardial infarction (AMI) comprises a significant proportion of autopsy cases. Troponin levels act as a specific and sensitive indicator of myocardial infarction. However, histological evaluation for the diagnosis of AMI remains the gold standard. This retrospective study was based on the total of 154 post-mortem cases and total of 85 emergency cases with Trop T samples sent for laboratory investigation in year 2016 at Hospital Kuala Lumpur. From the post-mortem cases, Trop $\mathrm{T}$ values for non-cardiac related death cases $(5.322 \mathrm{ng} / \mathrm{ml})$ were higher than cardiac-related death $(4.916 \mathrm{ng} / \mathrm{ml})$ with no significant difference between them although Trop $\mathrm{T}$ values were highly sensitive to myocardial infarction but the limitation was on the specificity. There was also no correlation between post-mortem Trop T levels to the cardiac-related cause of death using post-mortem cases. The minimum Trop $\mathrm{T}$ value amongst the MI post-mortem cases was assumed to be the cut-off value i.e. $\geq 0.390 \mathrm{ng} / \mathrm{ml}$. Although the elevated Trop T values might concur with the diagnosis of acute coronary syndrome causing subsequent death, there were multiple factors that can attribute to an elevated Trop $T$ results after death including post-mortem performing interval and depending on the severity of myocardial damage at the time of death. Eventually 38 emergency cases certified with MI were compared with 8 post-mortem cases certified with MI. The mean for post-mortem (PM) cases $(5.065 \pm 4.498 \mathrm{ng} / \mathrm{ml})$ was much higher than those ante-mortem (AM) case (1.327 $\pm 1.918 \mathrm{ng} / \mathrm{ml}$ ). Hence, there was statistically significant difference between ante-mortem and post-mortem cases presented with myocardial infarction. As such, post-mortem Trop T level could probably not be used to reflect the ante-mortem Trop $\mathrm{T}$ level to diagnose myocardial infarction. In addition, the effect of post-mortem performing interval was also statistically significant between interval of $<12$ hours and $12-48$ hours. A prospective study should be conducted by using the same patient diagnosed with myocardial infarction to analyse the ante-mortem and post-mortem Trop $\mathrm{T}$ value.

Keywords: Troponin T; Cardiac Death; Post-Mortem; Myocardial Infarction.

\section{Introduction}

In 21 st century, cardiac deaths accounted for $50 \%$ of all deaths in the developed and one fourth in the developing world. It is accepted universally that myocardial infarctions are foremost killers and destroyers of mankind today. By 2020, heart disease will lead to 25 million deaths all over the world annually. Indian people have been found to have the unfortunate distinction of having the highest prevalence of coronary artery disease among all ethnic groups in the world, the projected rise in the mortality rates
$(>100 \%)$ in the next 25 years. Acute myocardial infarction (AMI) is a serious and potentially lethal manifestation of coronary artery disease, affecting more than 7 million people worldwide each year and proved to be a cause of sudden death [1]. Sudden cardiac death due to an acute myocardial infarction (AMI) comprises a significant proportion of autopsy cases. In clinical practice, AMI is diagnosed with the aid of the electrocardiogram and serum biochemical markers specific in the detection of myocardial damage [2].

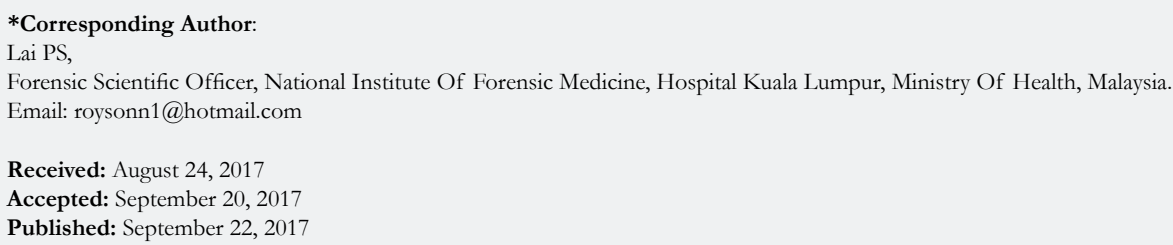

Citation: Lai PS, Nur Shafina M, Mohd Hilmi S, Nur Shazuwani R, Normaizuwana MM, et al., Correlation of Troponin T Levels in the Cardiac Sudden Death Cases at Hospital Kuala Lumpur. Int J Forensic Sci Pathol. 2017;5(6), 376-383. doi: http://dx.doi.org/10.19070/2332-287X-1700081

Copyright: Lai PS ${ }^{\circ}$ 2017. This is an open-access article distributed under the terms of the Creative Commons Attribution License, which permits unrestricted use, distribution and reproduction in any medium, provided the original author and source are credited. 
Troponin $\mathrm{T}$ and Troponin $\mathrm{I}$ in particular have been extensively studied and proof of sensitivity and specificity in detecting AMI is well established. Troponin is a complex of three regulatory proteins (Troponin C, I and T) that is integral to muscle contraction in skeletal and cardiac muscle. It is a component of thin filaments along with actin and tropomyosin and is the protein to which calcium binds to accomplish regulation of contraction and relaxation of the cardiac muscle. During myocardial injury, as seen in AMI, Troponin is released from the injured myocyte into the circulation which can be detected biochemically. The potential role however of Troponin in the diagnosis of AMI at post-mortem is less well known. In this study, we evaluate the sensitivity and specificity of Troponin $\mathrm{T}$ as a diagnostic tool in the detection of AMI at autopsy [2].

The limitations of autopsy in the diagnosis of death due to ischemic heart disease are well known. In the living, a simple reliable biochemical assay for cardiac troponins is used in the diagnosis of acute myocardial ischemia. Several studies have investigated the use of biochemical assays for cardiac troponins in post-mortem subjects as a means to distinguish between a cardiac and a noncardiac cause of death. All of these studies, however, rely upon assigning subjects to "cardiac" or "non-cardiac" death on the basis of a post-mortem examination. As post-mortem examination does not always accurately distinguish between these two groups, this approach is intrinsically flawed [3].

\section{Literature Review}

Sudden death accounts for approximately two thirds of autopsies in forensic medicine. Natural death within 1 hour after the beginning of acute symptoms is defined as sudden cardiac death. Due to ventricular fibrillation caused by myocardial irritability induced by ischemia or infarction. In post-mortem examination of dead bodies subjected to autopsy with probable sudden cardiac death, a diagnosis of myocardial infarction is usually made based on the finding of severe atherosclerosis occlusive coronary artery disease [1].

Actual detection of histological sequelae of the infarcted myocardium will develop, only after significant time lag between onset of myocardial infarction and death. Detectable loss of lactate dehydrogenase will be seen 5 hours after infarction using enzyme histo-chemistry. Recently several studies have shown keen interest on the application of biomarkers to diagnose AMI. The presence of cardiac biomarkers in blood with increased sensitivity to detect cardiac cell necrosis enables to diagnose AMI in $1 / 3^{\text {rd }}$ of patients who might not had accomplished the criteria for diagnosis of myocardial infarction [1].

Troponin is a protein complex, situated on the actin filament and regulates calcium mediated interaction of actin and myosin filaments during muscular contraction. It has three subunits cTnI (inhibitory), c'TnT (Tropomyosin Binding) and TnC (calcium binding). Cardiac Troponin $\mathrm{T}$ is the double filament protein and predominantly this protein is bound within myocytes, and less than $10 \%$ is dissolved in the cytosol [1].

Cardiac Troponin $\mathrm{T}$ is not normally present in the serum unless cardiac cell necrosis has occurred. Thus it is more cardiac specific. Recent studies have shown that cardiac Troponin levels act as a specific and sensitive indicator of myocardial infarction. The prognostic value of cardiac Troponin T is most important as it is not dependent on age, sex, ECG changes as well as levels of biochemical markers such as Creatine Kinase (CKMB). Cardiac Troponin $\mathrm{T}(\mathrm{c} T \mathrm{n} \mathrm{T})$ is elevated in all patients with acute myocardial infarction according to World Health Organization (WHO) criteria. Increased levels of cardiac Troponin $\mathrm{T}$ appears in the blood within 3-24 hours after AMI depending on factors such as infarct size and they can be estimated for up to 2 weeks in the living [1].

The cardiac Troponin-T assay is based on monoclonal antibody system using a poly-(streptavidin)-biotin capture system with a ruthenium complex cTnT in the blood sample or plasma combines with both the biotinylated Cardiac Troponin $\mathrm{T}$ and anti-Cardiac Troponin $\mathrm{T}$ and antibody. The European Society of Cardiology (ESC)/American College of Cardiology (ACC) guidelines recommend using 'the $99^{\text {th }}$ percentile of a healthy population as a cut-off for AMI using an assay with an acceptable precision. An acceptable precision has been defined as a co-efficient of variation $<10 \%$. For cardiac Troponin T, the $99^{\text {th }}$ percentile value of a healthy population is $0.1 \mathrm{ng} / \mathrm{ml}$; however, the $10 \%$ coefficient of variation requirement for the usual assay was met at a higher level (i.e. $0.3 \mathrm{ng} / \mathrm{ml}$ ). In clinical practice, the c'Tn'T assay has been approved for the diagnosis of AMI with high sensitivity and specificity [1].

A previous study compared antemortem and post-mortem cardiac troponin levels in five subjects. Erratic results bearing little or no relation to the antemortem cardiac troponin level were obtained for all subjects. Four of the five subjects had raised antemortem troponin levels, although only one had a cardiac cause of death. As such, post-mortem blood is not a suitable substrate for standard biochemical assays of cardiac troponins, which are designed for use on serum taken from living patients. In addition, the elevated cardiac troponins are a marker of serious morbidity and are not specific for cardiac injury as the primary cause of morbidity or mortality [3]. More findings from previous study confirm that while Troponin $\mathrm{T}$ is a sensitive marker in the detection of AMI at autopsy it is not specific and therefore cannot be used as a diagnostic tool at autopsy. There are multiple factors that can attribute to an elevated Troponin T result following death. Histological evaluation for the diagnosis of AMI remains the gold standard [3].

Forensic pathologists seldom request Troponin assay/test in the investigation of sudden cardiac death because of firm diagnosis of cardiac death as evident on gross autopsy and histological findings coupled with significant symptoms. However not all cardiac deaths show these finding e.g. microinfarcts of the myocardium may produce cardiac arrhythmias and subsequent death. The sensitive markers should be that highest abundance in the cell. The major function of the heart is contraction, the proteins involved in contraction in producing the energy are important biomarkers of cardiac injury which could be detected in blood and cardio specific proteins like Cardiac Troponin T levels are more sensitive and specific biomarkers [1].

A study showed that the elevated levels were normally seen in post-mortem control samples. Although, blood from central locations as the cardiac ventricles and pericardial fluid showed markedly increased levels, they best equate ante-mortem physiologic levels. 
Moreover, it is necessary to correlate the laboratory reports with the place of occurrence, history of the case, and HPE findings. One issue with this study and studies up to date is that cardiac Troponin $\mathrm{T}$ levels are tested in obvious patients with acute MI and compared with patients who died of non-cardiac causes. Inevitably, all of these studies concluded that increased cardiac Troponin $\mathrm{T}$ levels correlate with the cause of death and supported the gross and HPE findings. Therefore more large scale studies are needed before definite conclusions can be drawn from these assays [1].

Another study was conducted with a comprehensive analysis of cardiac, peripheral blood and pericardial levels of cardiac troponin $\mathrm{T}(\mathrm{c} T \mathrm{~T} \mathrm{~T})$ in serial medicolegal autopsy cases $(\mathrm{n}=405)$ with a survival time $<24 \mathrm{~h}$ and within $48 \mathrm{~h}$ post-mortem to assess the validity of investigating myocardial damage with special regard to traumatic causes of death. Cases within $12 \mathrm{~h}$ post-mortem usually showed lower cardiac and pericardial cTnT levels than did those of longer post-mortem time of $12-48 \mathrm{~h}$. The elevation of cTnT was associated with the pathology of advanced myocardial damage involving swelling and liquefactive necrosis. These differences were the smallest for peripheral blood. These findings suggest that elevations in post-mortem serum and pericardial c'TnT levels depend on the severity of myocardial damage at the time of death and are related to the pathological findings, although post-mortem interference should be taken into consideration [4].

\section{Objectives}

\section{General Objectives}

1. To determine the correlation of Troponin $\mathrm{T}$ value for postmortem blood samples in the cardiac sudden death cases.

\section{Specific Objectives}

1. To correlate the ante-mortem Troponin T levels to the myocardial infarction death using emergency cases.

2. To correlate the post-mortem Troponin T levels to the myocardial infarction death using post-mortem cases.

3. To determine the difference of ante-mortem and post-mortem Troponin $\mathrm{T}$ levels using emergency cases and subsequent post-mortem cases.

\section{Methodology}

This was a retrospective cross-sectional study. Total of 154 Postmortem cases and another total of 85 Emergency cases with Troponin T samples sent for Laboratory Investigation in 2016 at Hospital Kuala Lumpur. All the post-mortem cases and emergency cases with blood samples sent for Troponin $\mathrm{T}$ investigation in year 2016 were retrieved from Forensic Medicine Information System (FMIS). Cardiac-related death was divided into four categories including Myocardial Infarction (MI), Ischemic Heart Disease (IHD), Coronary Artery-related Disease (CA) and Heartrelated Disease (HD). Non-cardiac related death was labelled as others $(\mathrm{O})$. Interval of post-mortem conducted was computed from time since death or time of body receiving whichever was earlier. Troponin $\mathrm{T}$ levels were retrieved retrospectively from the Laboratory Information System (LIS) for the inclusion cases. Statistical tests i.e. Chi-square test, Mann-Whitney test, Two-way ANOVA and Spearman Correlation test were used to analyze the results. No ethical approval was required as only patients data were utilized without any clinical intervention.

\section{Results And Discussion}

Out of the 154 post-mortem cases included in year 2016, total of 138 cases were reported with Trop $\mathrm{T}$ values and the rest were unable to proceed for analysis due to sample severely lysed. From there, 90 cases $(65.2 \%)$ were certified with cardiac-related death and 48 cases $(34.8 \%)$ were certified with non-cardiac related death (Table 1). The Trop T means of the respective category of cardiac-related death was highest in MI cases $(5.065 \mathrm{ng} / \mathrm{ml})$, followed by IHD cases $(4.936 \mathrm{ng} / \mathrm{ml})$, CA cases $(4.895 \mathrm{ng} / \mathrm{ml})$ and HD cases $(4.682 \mathrm{ng} / \mathrm{ml})$. However, Trop T means for non-cardiac related death $(\mathrm{O})$ superseded all the cardiac-related death categories with $5.322 \mathrm{ng} / \mathrm{ml}$ (Figure 1).

As the MI cases were analysed with higher mean values compared to other cardiac-related death cases, high Trop $\mathrm{T}$ values could be relatively higher sensitive to MI cases but the specificity was limited due to heart-related disease (HD) also presented with high upper bound $95 \%$ confidence interval of Trop $\mathrm{T}$ values, supported by Han \& Flavin (2014). There was no significant differences of Trop $T$ values between the non-cardiac related death and cardiac related death. In other words, both could not be distinguished as stated by Davies et al., (2005). It was also true within cardiac-

Table 1. Descriptive Table of Trop T Values for Post-mortem Cases in 2016.

\begin{tabular}{|c|c|c|c|c|c|c|c|c|}
\hline \multicolumn{9}{|c|}{ Descriptives } \\
\hline & \multirow{2}{*}{$\mathbf{N}$} & \multirow{2}{*}{ Mean } & \multirow{2}{*}{$\begin{array}{c}\text { Std. } \\
\text { Deviation }\end{array}$} & \multirow{2}{*}{$\begin{array}{l}\text { Std. } \\
\text { Error }\end{array}$} & \multicolumn{2}{|c|}{$\begin{array}{l}95 \% \text { Confidence } \\
\text { Interval for Mean }\end{array}$} & \multirow{2}{*}{ Min } & \multirow{2}{*}{ Max } \\
\hline & & & & & $\begin{array}{l}\text { Lower } \\
\text { Bound }\end{array}$ & $\begin{array}{l}\text { Upper } \\
\text { Bound }\end{array}$ & & \\
\hline $\mathrm{O}$ & 48 & 5.3221 & 4.39496 & .63436 & 4.0459 & 6.5983 & .04 & 10.00 \\
\hline MI & 8 & 5.0650 & 4.49790 & 1.59025 & 1.3047 & 8.8253 & .39 & 10.00 \\
\hline IHD & 45 & 4.9361 & 4.19867 & .62590 & 3.6747 & 6.1976 & .02 & 10.00 \\
\hline $\mathrm{CA}$ & 31 & 4.8949 & 4.27361 & .76756 & 3.3273 & 6.4624 & .01 & 10.00 \\
\hline $\mathrm{HD}$ & 6 & 4.6815 & 4.74652 & 1.93776 & -.2997 & 9.6627 & .05 & 10.00 \\
\hline Total & 138 & 5.0575 & 4.26441 & .36301 & 4.3397 & 5.7753 & .01 & 10.00 \\
\hline
\end{tabular}


Figure 1. Means of Trop T Values for Cardiac and Non-Cardiac Death Cases.

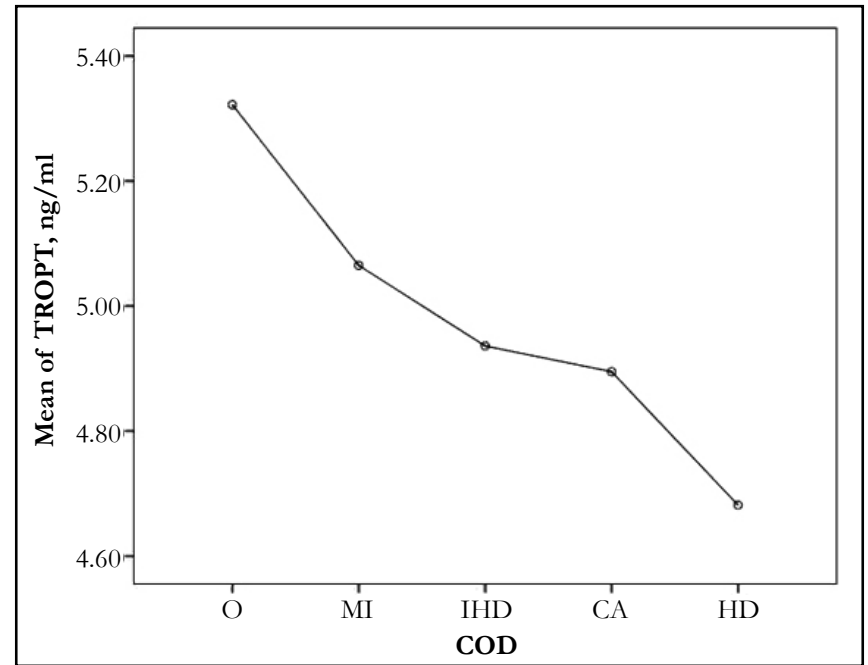

Table 2. Chi-Square Statistic Analysis of Trop T values between COD Groups.

\begin{tabular}{|c|c|c|c|}
\hline & Value & df & Asymp. Sig. (2-sided) \\
\hline Pearson Chi-Square & $339.302^{\mathrm{a}}$ & 312 & 0.138 \\
Likelihood Ratio & 230.767 & 312 & 1 \\
Linear-by-Linear Association & 0.296 & 1 & 0.587 \\
N of Valid Cases & 138 & & \\
\hline
\end{tabular}

a. 392 cells $(99.2 \%)$ have expected count less than 5. The minimum expected count is .04.

related death categories (Table 2).

As inference made based on Spearman Correlation $(p=0.382$, $\mathrm{p}>0.05$ ), there was no correlation between post-mortem Trop $T$ levels to the cardiac-related cause of death using post-mortem cases. In order to determine the reference values of Trop $\mathrm{T}$ for post-mortem blood samples in correlation with cardiac-related death and specifically myocardial infarction, the minimum Trop $\mathrm{T}$ values amongst $\mathrm{MI}$ post-mortem cases was assumed to be the reference value i.e. $\geq 0.390 \mathrm{ng} / \mathrm{ml}$. This value did not deviated much from variation requirement for usual assay at $0.3 \mathrm{ng} / \mathrm{ml}$ mentioned by Bheeshma et al., (2015).

From the 138 cases, only two cases ware analysed with ante-mortem and post-mortem Trop $\mathrm{T}$ levels. Those cases were dead-inward (DIW) under emergency management. The Trop T level of one of the patients was $0.007 \mathrm{ng} / \mathrm{ml}$ on 20/5/2016 $10.32 \mathrm{AM}$ and the patient subsequently pronounced dead at 2.35 PM after 4 hours. Post-mortem was performed on the patient at 6.00 PM. The Trop T was raised to $1.04 \mathrm{ng} / \mathrm{ml}$ after $3 \frac{1}{2}$ hours. The body was eventually certified as Coronary Artery Disease (CA) based on histological findings. Another patient was admitted on $28 \mathrm{Oct}$ $20161.05 \mathrm{AM}$, the initial Trop T level was $<0.003 \mathrm{ng} / \mathrm{ml}$. The Trop T raised to $0.738 \mathrm{ng} / \mathrm{ml}$ after $4 \frac{1}{2}$ hours at $5.44 \mathrm{AM}$ and the patient subsequently pronounced dead at 10.10 AM. Post-mortem was performed on the patient at 5.00 PM. The Trop T was steeply raised again by 12.5 times to $9.2 \mathrm{ng} / \mathrm{ml}$ after another $41 / 2$ hours. Throughout the 9 hours period, it was concurred with the diagnosis of acute coronary syndrome as shown in Figure 2 and eventually, it was certified as Ischemic Heart Disease (IHD) based on histological findings. However, there were multiple factors that can attribute to an elevated Trop $T$ results after death according to
Han \& Flavin (2014) including the interval from time of death to time of postmortem and depending on the severity of myocardial damage at the time of death stated by Zhu et al., (2006).

This retrospective study could not control the perfect timing of ante-mortem blood taking which should be logically not more than 15 minutes prior to death. As such ante-mortem and postmortem paired-sample comparison could not be conducted due to the increasing trend. Otherwise, there was definitely significant difference between ante-mortem and post-mortem because of the raising Trop $\mathrm{T}$ values until the point of death pronounced. Although another 7 cases of DIW with cardiac-related COD were traced from year 2011 - 2017, there was no ante-mortem blood taken for Trop $\mathrm{T}$ analysis to compare with post-mortem Trop T levels. These cases measured with average $6.128 \mathrm{ng} / \mathrm{ml}$ for post-mortem Trop T levels and $57.14 \%$ of them with $10 \mathrm{ng} / \mathrm{ml}$ particularly sensitive to ischemic heart disease and coronary artery disease, yet no significant differences between them.

The alternative way of ante-mortem and post-mortem comparison was by using independent samples. Out of the 85 emergency cases included in year 2016, total of 40 cases were certified with non-cardiac related death and 45 cases were reported with cardiac related death. Within the cardiac-related death cases, noticed that there were only two categories of cardiac-related COD including $84.4 \%$ myocardial infarction (MI) and $15.6 \%$ heart-related disease (HD). Again the average Trop T value for MI cases $(1.327 \mathrm{ng} / \mathrm{ml})$ was slightly higher than the HD cases $(0.455 \mathrm{ng} / \mathrm{ml})$ as shown in Table 3.

The average Trop $\mathrm{T}$ value for non-cardiac related death cases was the lowest i.e. $0.4267 \mathrm{ng} / \mathrm{ml}$ amongst all categories. There was a 
Figure 2. Trop T levels of Acute Coronary Syndrome.

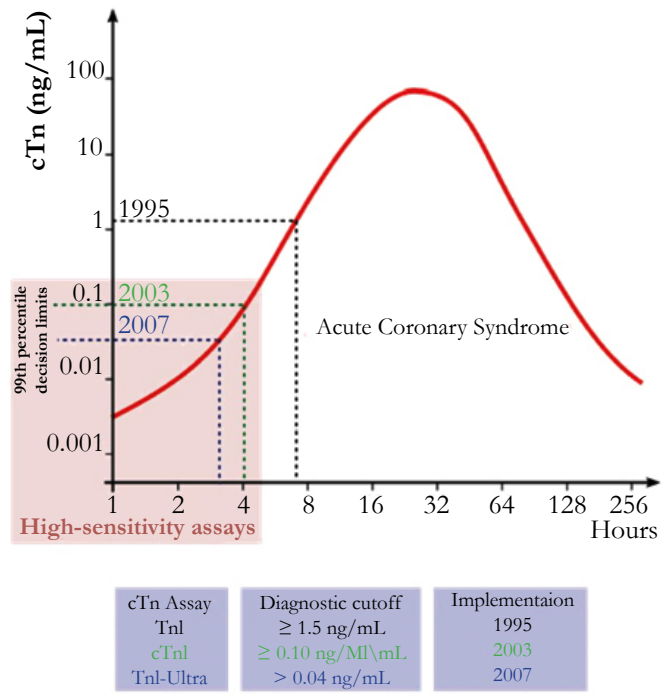

Table 3. Descriptive Table of Trop T Values for Emergency Cases in 2016.

\begin{tabular}{|c|c|c|c|c|c|c|c|c|}
\multicolumn{1}{c|}{} & & & Mean & $\begin{array}{c}\text { Std. } \\
\text { Deviation }\end{array}$ & \multirow{2}{*}{$\begin{array}{c}\text { Std. } \\
\text { Error }\end{array}$} & N & Mescriptive & \multicolumn{2}{c|}{$\begin{array}{c}\mathbf{9 5 \%} \text { Confidence } \\
\text { Interval for Mean }\end{array}$} & \multirow{2}{*}{ Min } & Max \\
\cline { 6 - 9 } & & & & $\begin{array}{c}\text { Lower } \\
\text { Bound }\end{array}$ & $\begin{array}{c}\text { Upper } \\
\text { Bound }\end{array}$ & \\
\hline O & 40 & 0.427 & 1.588 & 0.251 & -0.081 & 0.935 & .00 & 10 \\
\hline MI & 38 & 1.327 & 1.918 & 0.311 & 0.697 & 1.957 & 0.01 & 7.02 \\
\hline HD & 7 & 0.455 & 0.744 & 0.281 & -0.233 & 1.143 & 0.02 & 2.02 \\
\hline Total & 85 & 0.831 & 1.741 & 0.189 & 0.456 & 1.207 & .00 & 10 \\
\hline
\end{tabular}

Figure 3. Means of Trop T Values for Cardiac and Non-Cardiac Death Cases.

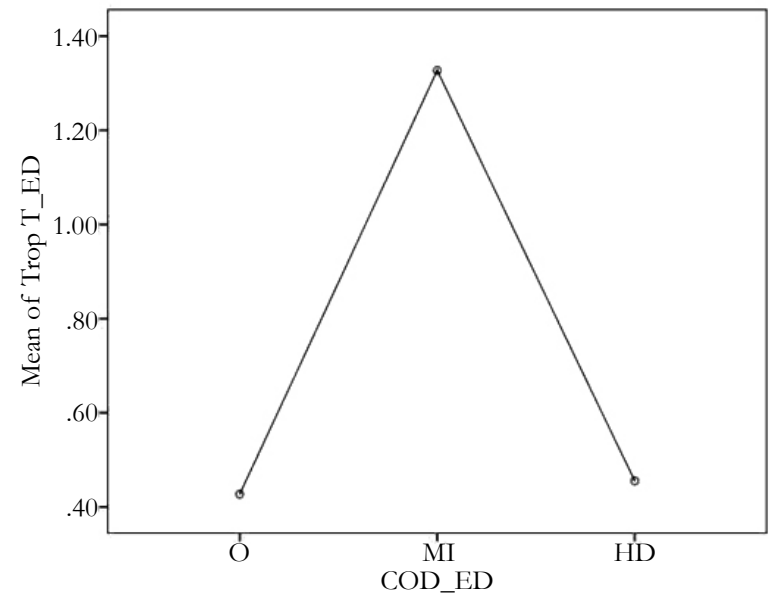

significant difference between groups as shown in the Kruskal Wallis test with $\mathrm{p}=0.006(\mathrm{p}<0.05)$ and it also revealed through the ANOVA test that the significant difference was mainly contributed by the Trop $\mathrm{T}$ values between the non-cardiac related death with myocardial infarction death i.e. $\mathrm{p} \approx 0.05$. (Table 4).

Mann-Whitney statistical analysis showed in Table 5 that $\mathrm{p}=$ 0.228 ( $p>0.05$ ) i.e. there was no significant difference between these two COD categories within emergency cases (Figure 3). As such it could be inferred, based on Spearman Correlation where $p=0.232, p>0.05$, that there was no correlation between antemortem Trop $\mathrm{T}$ levels to the types of cardiac-related death using emergency cases.

From the total of 46 emergency cases included, there were 38 cases certified with MI could be compared with 8 post-mortem cases certified with MI by using Mann-Whitney test. The mean for post-mortem $(\mathrm{PM})$ cases $(5.065 \pm 4.498 \mathrm{ng} / \mathrm{ml})$ was much higher than those ante-mortem (AM) case $(1.327 \pm 1.918 \mathrm{ng} /$ $\mathrm{ml})$. Hence, statistics analysis showed $\mathrm{p}=0.005(\mathrm{p}<0.05)$ i.e. there was significant difference between ante-mortem and postmortem cases presented with myocardial infarction diagnosis (Table 6). It was also happened to be true difference for those non-cardiac related death cases. As such, post-mortem Trop T 
Table 4. Kruskal Wallis Statistical Test of Trop T values for Emergency Cases.

Test Statistics ${ }^{\mathrm{a}, \mathrm{b}}$

\begin{tabular}{|c|c|}
\hline & TropT_ED \\
\hline Chi-Square & 10.122 \\
df & 2 \\
Asymp. Sig. & 0.006 \\
\hline
\end{tabular}

a. Kruskal Wallis Test

b. Grouping Variable: COD_ED

Multiple Comparisons

Dependent Variable: Trop'T_ED

\begin{tabular}{|c|c|c|c|c|c|c|c|}
\hline & \multirow{2}{*}{ (I) COD_ED } & \multirow{2}{*}{ (J) COD_ED } & \multirow{2}{*}{$\begin{array}{c}\text { Mean } \\
\text { Difference (I-J) }\end{array}$} & \multirow{2}{*}{ Std. Error } & \multirow{2}{*}{ Sig. } & \multicolumn{2}{|c|}{ 95\% Confidence Interval } \\
\hline & & & & & & Lower Bound & Upper Bound \\
\hline \multirow{4}{*}{ Tukey HSD } & \multirow{2}{*}{$\mathrm{O}$} & MI & -.90017 & .38571 & .057 & -.8209 & .0205 \\
\hline & & HD & -.02833 & .69760 & .999 & -.6935 & 1.6368 \\
\hline & \multirow{2}{*}{ MI } & $\mathrm{O}$ & .90017 & .38571 & .057 & -.0205 & 1.8209 \\
\hline & & HD & .87182 & .70033 & .430 & -.7998 & 2.5435 \\
\hline
\end{tabular}

Table 5. Mann-Whitney Statistical Test of Trop T values for Emergency Cases.

Test Statistics ${ }^{\mathrm{a}}$

\begin{tabular}{|c|c|}
\hline & TropT_ED \\
\hline Mann-Whitney U & 94.5 \\
\hline Wilcoxon W & 122.5 \\
\hline Z & -1.206 \\
\hline Asymp. Sig. (2-tailed) & 0.228 \\
\hline Exact Sig. [2*(1-tailed Sig.)] & $.234 \mathrm{~b}$ \\
\hline
\end{tabular}

a. Grouping Variable: COD_ED

Table 6. Mann-Whitney Statistical Test of Trop T values for PM and AM Cases.

Test Statistics ${ }^{\mathrm{a}}$

\begin{tabular}{|c|c|}
\hline & TropT_PM_AM \\
\hline Mann-Whitney U & 54.000 \\
\hline Wilcoxon W & 795.000 \\
\hline Z & -2.841 \\
\hline Asymp. Sig. (2-tailed) & .005 \\
\hline Exact Sig. [2*(1-tailed Sig.)] & $.003^{\mathrm{b}}$ \\
\hline
\end{tabular}

a. Grouping Variable: PM_AM

b. Not corrected for ties

level could probably not be used to reflect the ante-mortem Trop $\mathrm{T}$ levels to diagnose myocardial infarction. However, there were many factors affecting this results including independent samples were used and the blood for Trop T analysis was taken at different time interval and the elevated Trop $\mathrm{T}$ should be observed prior to death.

Nevertheless, post-mortem should be performed earlier within 12 hours because higher level of Trop $T$ would be presented if postmortem after 12 - 48 hours (Zhu et al., 2006). This was supported by the findings from this study using the post-mortem cases as shown in Table 7 and Table 8 by dividing the post-mortem per- forming interval into $<12$ hours $(3.947 \pm 4.078 \mathrm{ng} / \mathrm{ml})$ and 12 - 48 hours $(7.597 \pm 3.568 \mathrm{ng} / \mathrm{ml})$.

As shown in Table 8, there was significant difference between the two intervals, $\mathrm{p}<0.001$. The effect of post-mortem performing interval was also statistically significant $\mathrm{p}<0.001$ but no significant effect was contributed from the cause of death. The Trop $T$ value based on the post-mortem performing interval was also significantly different between non-cardiac related death and car- diacrelated death as well as within the four categories of cardiac related death. Average Trop T values for cardiac related death cases were $4.23 \mathrm{ng} / \mathrm{ml}$ and $6.82 \mathrm{ng} / \mathrm{ml}$ in average for the $<12$ hours 
and 12 - 48 hours post-mortem performing interval respectively. This was supported by the findings by Zhu et al., (2006).

By referring to Table 9, four scenario of cases could be compared with their respective Trop $\mathrm{T}$ levels whereby resuscitation been performed prior to death. According to the similar intervals in scenario 1 and 3, it has shown a huge different whereby scenario 1 increased $8.462 \mathrm{ng} / \mathrm{ml}$ while not significant changes i.e. 1.033 $\mathrm{ng} / \mathrm{ml}$ in scenario 3 . This was clearly deviated from the graph displayed in Figure 3 where scenario 3 has increased in faster rate by twice the intervals i.e. it should take longer periods or at least 8 hours for the changes of Trop $T$ values. In addition, scenario 4 has clearly shown that there was post-mortem changes in Trop $\mathrm{T}$ value because Trop $\mathrm{T}$ was relatively low at 37 minutes prior to death, however it was detected at $10 \mathrm{ng} / \mathrm{ml}$ after 25 hours using the post-mortem samples. This was again supported by the findings by Zhu et al., (2006). The main limitation of this study was that there was no paired-sample analysis could be conducted due to independent samples were used. As such, a prospective study should be conducted by using the same patient diagnosed with myocardial infarction to analyse the ante-mortem and post-mortem Trop $\mathrm{T}$ value at certain control interval. There was no significant difference between scenario 2 and 3 certified with same COD even if the intervals were prolonged.

\section{Conclusion}

This retrospective study was based on the total of 154 post-mortem cases and total of 85 emergency cases with Trop T samples sent for laboratory investigation in year 2016 at Hospital Kuala Lumpur. From the post-mortem cases, Trop T values for noncardiac related death cases $(5.322 \mathrm{ng} / \mathrm{ml})$ were higher than cardiac-related death $(4.916 \mathrm{ng} / \mathrm{ml})$ and there was no significant difference between them, although Trop T values were highly sensitive to myocardial infarction but the limitation was on the specificity. There was also no correlation between post-mortem Trop T levels to the cardiac-related cause of death using post-mortem cases. The minimum Trop T value amongst the MI post-mortem cases

Table 7. Mann-Whitney test and Two-way ANOVA Test.

Test Statistics ${ }^{\mathrm{a}}$

\begin{tabular}{|c|c|}
\hline & TROPT \\
\hline Mann-Whitney U & 991.000 \\
\hline Wilcoxon W & 5647.000 \\
\hline Z & -4.828 \\
\hline Asymp. Sig. (2-tailed) & .000 \\
\hline
\end{tabular}

a. Grouping Variable: Interval.

Table 8. Two-way ANOVA between Interval and COD Variables for Postmortem.

Tests of Between-Subjects Effects

Effects Dependent Variable: TROPT

\begin{tabular}{|c|c|c|c|c|c|}
\hline Source & $\begin{array}{c}\text { Type III Sum of } \\
\text { Squares }\end{array}$ & df & Mean Square & F & Sig. \\
\hline Corrected Model & $464.685^{\text {a }}$ & 9 & 51.632 & 3.261 & .001 \\
\hline Intercept & 1701.182 & 1 & 1701.182 & 107.442 & .000 \\
\hline COD & 12.739 & 4 & 3.185 & .201 & .937 \\
\hline Interval & 139.939 & 1 & 139.939 & 8.838 & .004 \\
\hline COD * Interval & 65.925 & 4 & 16.481 & 1.041 & .389 \\
\hline Error & 2026.688 & 128 & 15.834 & & \\
\hline Total & 6021.200 & 138 & & & \\
\hline Corrected Total & 2491.374 & 137 & & & \\
\hline
\end{tabular}

a. R Squared $=.187($ Adjusted R Squared $=.129)$

Table 9. Ante-mortem and post-mortem Trop $\mathrm{T}$ comparison with analysis of intervals.

\begin{tabular}{|c|c|c|c|c|c|}
\hline No & $\begin{array}{c}\text { Ante-mortem } \\
\text { Trop T Level }\end{array}$ & $\begin{array}{c}\text { Interval of ante- } \\
\text { mortem till death }\end{array}$ & $\begin{array}{c}\text { Interval of death } \\
\text { till post-mortem }\end{array}$ & $\begin{array}{c}\text { Post-mortem } \\
\text { Trop T Level }\end{array}$ & COD \\
\hline 1 & $0.738 \mathrm{ng} / \mathrm{ml}$ & 4 hours 26 mins & 4 hours $50 \mathrm{mins}$ & $9.200 \mathrm{ng} / \mathrm{ml}$ & IHD \\
\hline 2 & $0.914 \mathrm{ng} / \mathrm{ml}$ & 19 hours $22 \mathrm{mins}$ & 10 hours $27 \mathrm{mins}$ & $3.440 \mathrm{ng} / \mathrm{ml}$ & $\mathrm{CA}$ \\
\hline 3 & $0.007 \mathrm{ng} / \mathrm{ml}$ & 4 hours $3 \mathrm{mins}$ & 3 hours $25 \mathrm{mins}$ & $1.040 \mathrm{ng} / \mathrm{ml}$ & $\mathrm{CA}$ \\
\hline 4 & $0.021 \mathrm{ng} / \mathrm{ml}$ & $37 \mathrm{mins}$ & 25 hours $2 \mathrm{mins}$ & $10.000 \mathrm{ng} / \mathrm{ml}$ & MI \\
\hline
\end{tabular}


was assumed to be the cut-off value i.e. $\geq 0.390 \mathrm{ng} / \mathrm{ml}$. Although the elevated Trop $\mathrm{T}$ values might concur with the diagnosis of acute coronary syndrome causing subsequent death, there were multiple factors that can attribute to an elevated Trop T results after death and depending on the severity of myocardial damage at the time of death. The average Trop T value for MI emergency cases was slightly higher than the HD emergency cases, however, it was not statistically significant. There was no significant difference and no correlation between ante-mortem Trop $\mathrm{T}$ levels to the types of cardiac-related death using emergency cases. Eventually 37 emergency cases certified with MI were compared with 8 post-mortem cases certified with MI. The mean for post-mortem $(\mathrm{PM})$ cases $(5.065 \pm 4.498 \mathrm{ng} / \mathrm{ml})$ was much higher than those ante-mortem (AM) case $(1.327 \pm 1.918 \mathrm{ng} / \mathrm{ml})$. Hence, there was statistically significant difference between ante-mortem and postmortem cases presented with myocardial infarction diagnosis. As such, post-mortem Trop T level could probably not be used to reflect the ante-mortem Trop $\mathrm{T}$ level to diagnose myocardial infarction. In addition, the effect of post-mortem performing interval was statistically significant between interval of $<12$ hours and 12
- 48 hours. A prospective study should be conducted by using the same patient diagnosed with myocardial infarction to analyse the ante-mortem and post-mortem Trop $T$ value at certain control interval.

\section{References}

[1]. B Bheeshma, V Geetha, Jay Raju, Sandhya Manohar. Cardiac Troponin-T levels in heart blood as a marker to diagnose post-mortem myocardial infarction. IAIM. 2015;2(3): 108-118.

[2]. Han K, Flavin R. Troponin T as a Diagnostic Marker in the Detection of Acute Myocardial Infarction at Autopsy. Int J Forensic Sci Pathol. 2014 May;2(4): 28-29.

[3]. Davies SJ, Gaze DC, Collinson PO. Investigation of cardiac troponins in post-mortem subjects: comparing antemortem and post-mortem levels. Am J Forensic Med Pathol. 2005 Sep;26(3):213-5.

[4]. Zhu BL, Ishikawa T, Michiue T, Li DR, Zhao D, Oritani S, et al. Postmortem cardiac troponin $T$ levels in the blood and pericardial fluid. Part 1. Analysis with special regard to traumatic causes of death. Leg Med (Tokyo). $2006 \mathrm{Mar} ; 8(2): 86-93$. 